\title{
Panel Causality between Financial Development and Economic Growth in Africa
}

\author{
Babayemi ${ }^{1}$, A.W., Asare ${ }^{2}$, B. K.,Gulumbe S.U. ${ }^{2}$, Onwuka, G.I ${ }^{1}$., James, T.O ${ }^{1}$. \\ ${ }^{I}$ Kebbi State University of Science and Technology, Aliero, Kebbi State, Nigeria \\ ${ }^{2}$ Usmanu Danfodiyo University, Sokoto
}

\begin{abstract}
This research work investigated the panel of seven African Countries from 1990 to 2015 with a view to determine the direction of causality between the financial development and economic growth in Africa. Dumitrescu-Hurlin Panel Causality test was implemented and the results across the countries under study revealed thatit is strongly evident to reject the null that market value does not homogeneously cause economic growth.This tends to imply that market value across the countries can be used to predict the economic growth in the long run. Similarly, there is strong evidence to reject the null that inflation does not homogenously cause economic growthwhich tends to imply that there is causality effect of inflation on the economic growth of these African countries.
\end{abstract}

\section{Background to the Study}

Most of the literature has documented the link between the financial development, macroeconomic variables and the long-run economic growth, both at time series and panel data settings. The interest here is to examine the direction of causalitybetween the financial development and economic growth in Africa in panel in setting to prevent the misleading information as regard the panel under investigation. To arrive at a good policy decision there is need for proper evaluation of models that brought about the decision or action to be taken. In fact, Indrani (2007) argued that it is not just a matter of intellectual curiosity to examine the nexus between the financial development and economic growth of nations but also as a crucial policy issue. Allen and Gale (1999) clarified that financial development can be categorized as either bank based type or stock market based type. The advocates of bank based financial development argued the crucial role the banking development plays in economic growth of any nation and that this serves as an effective upper hand over stock market based financial development. The risks that accompany the flow of information on stock market floors are due to the asymmetric effects which are of higher risk compared with the risk in the banking arena. The proponents of the stock market based type on the other hand are of the opinion that a well-functioning stock market brings about growth and investments in a nation. These investments are more effective and efficient in promoting economic growth compared with the bank credits (Levine, 2002 and Beck and Levine, 2002). Recently research carried out by Adnan (2011) has clearly classified the determinants of financial development into two main groups. The first group measures the financial system based on the observed outcomes of its determinants such as size, access and depths. Since the observed outcomes are done along with time period, hence this group is termed as time variant group. On the other hand, the second group measures the determinant of the financial development through country's legal might, business activities (small scale enterprises), political and financial stability and is termed as time invariant group. This research work adopted the former, and hence considers financial deepening and financial sophistication as the components of financial development.

Many models in this area emphasize that well-functioning financial intermediaries and markets ameliorate information and cost of transaction thereby fostering efficient resource allocation and hence fostering long-run growth (Bencivenga and Smith, 1991); (Bencivenga, et al., 1995); (Laurent et al., 2011); and (Adusei, 2013).

In the developing countries of Africa however, financial development facilitates long- run economic development by expanding the banking system and stock markets, and making controls for some macroeconomic variables such as foreign direct investment, inflation, term trade, broad money and so on (see for example Levine, 2002). It is worth noting that the urge and interest to investigate the direction of causality of financial systems in African countries are motivated by the quest to know in the long run the impact of these financial intermediaries on the economic growth of Africa using up-to-date panel modelling procedures. In this regard, Dumitrescu-Hurlin (2012) panel non-causality test to investigate in panel setting, the flow of directions of causality between all the five determinants of development across these countries under study.

This work selects seven African stock markets based on the performance of their stock market values for the periods under investigation. On this basis, the African stock markets considered are those of Botswana, Egypt, Ghana, Kenya, Morocco, Nigeria and South Africa. For more details see (Nile Capital Management, 2011; Babayemi and Asare, 2014). However, this research work investigated the panel of these seven African 
Countries from 1990 to 2015 with a view to determine the direction of causality between the financial development and economic growth in Africa. This work will tend to help the researchers, financial practitioners, potential investors and policy makers in the area of decision making and regulatory frame work of financial institutions such as stock markets, banks and other non-banking intermediaries and also add to the existing African literature on the relationship between financial and developmental variables and the long-run economic growth.

\subsection{Introduction}

\section{Methodology}

Dumitrescu and Hurlin (2012) proposed a similar bivariate testing procedure to Granger (1969) causality test in a panel setting. This test makes an extreme opposite assumption to Granger Causality test, allowing all coefficients to be different across cross-sections. Their testing approach takes into account (i) the heterogeneity of the regression model used to test the Granger causality test and (ii) heterogeneity of the causality relationships over the cross-section dimension under the null hypothesis that there is no causal relationship for any of the units of the panel (i.e., homogeneous non-causality)

\subsection{Datasets}

This study uses annual panel datasets of seven African countries from 1988 to 2014. The seven countries are Botswana, Egypt, Ghana, Kenya, Morocco, Nigeria and South Africa, and the datasets are sourced from the World Bank Databank and the International Monetary Fund Databank. The panel datasets consist of market value ( $\left.m k t_{-} v a l\right)$, domestic credit to private sector by banks (bnk_cr), annual percentage growth rate of GDP $(g d p)$, ratio of broad money to narrow money $\left(\mathrm{M}_{2} / \mathrm{M}_{1}\right)$, inflation (inf), broad money $\left(M_{2}\right)$, total external debt stocks to Gross National Income (ext_dbt), and total net inflows $(f d i)$. These countries are included on the basis of the performances of their market capitalization to GDP for the period under investigation.

\subsection{Dumitrescu-Hurlin Panel Non-causality Test}

The general pair of panel Granger causality models is given by

$$
\begin{aligned}
y_{i, t}=\alpha_{0, i}+\alpha_{1, i} y_{i, t-1}+\cdots+\alpha_{l, i} y_{i, t-1}+\beta_{1, i} x_{i, t-1}+\cdots+\beta_{l, i} x_{i, t-1}+\varepsilon_{i, t} \\
x_{i, t}=\alpha_{0, i}+\alpha_{1, i} x_{i, t-1}+\cdots+\alpha_{l, i} x_{i, t-1}+\beta_{1, i} y_{i, t-1}+\cdots+\beta_{l, i} y_{i, t-1}+\varepsilon_{i, t}
\end{aligned}
$$

while Granger causality test tests for the null of the pair:

$\alpha_{0, i}=\alpha_{0, j}, \alpha_{1, i}=\alpha_{1, j}, \ldots, \alpha_{l, i}=\alpha_{l, j}, \forall i, j$

$\beta_{1, i}=\beta_{1, j}, \ldots, \beta_{l, i}=\beta_{l, j}, \forall i, j$

Dumitrescu and Hurlin (2012) tests the causality for the null of the pair:

$$
\begin{gathered}
\alpha_{0, i} \neq \alpha_{0, j}, \alpha_{1, i} \neq \alpha_{1, j}, \ldots, \alpha_{l, i} \neq \alpha_{l, j}, \forall i, j \\
\beta_{1, i} \neq \beta_{1, j}, \ldots, \beta_{l, i} \neq \beta_{l, j}, \forall i, j
\end{gathered}
$$

There are two different distributions in this test: asymptotic and semi-asymptotic. Asymptotic distribution is used when $\mathrm{T}>\mathrm{N}$, while semi-asymptotic distributions used when $\mathrm{N}>\mathrm{T}$. Dumitrescu and Hurlin (2012) put the pair of Homogeneous Non-Causality (HNC) null and alternate Hypotheses as:

$H_{0}: \beta_{i}=0 \forall i \quad$ with $\quad\left(\beta_{i}=\beta_{1, i}=\beta_{1, j}, \ldots, \beta_{l, i}=\beta_{l, j}\right)$

$H_{1}: \beta_{i} \neq 0 \forall i=1, \ldots, N_{1}$

$$
\beta_{i} \neq 0 \forall i=N_{1}+1, N_{1}+2, \ldots, N
$$

This alternative hypothesis of HNC allows for some of the individual vectors $\beta_{i}$ to be equal to zero. For the Dumitrescu-Hurlin test, the average statistic $W_{N, T}^{H N C}$ hypothesis can be written as follows:

$W_{N, T}^{H N C}=\frac{1}{N} \sum_{i=1}^{N} W_{i, T}$

Here, $W_{i, T}$ stands for the individual Wald statistical values for cross-section units and the average statistic $W_{N, T}^{H N C}$, which has asymptotic distribution for $\mathrm{T}>\mathrm{N}$, associated with the null of $\mathrm{HNC}$ hypothesis, is defined as:

$$
Z_{N, T}^{H N C}=\sqrt{\frac{N}{2 K}}\left(W_{N, T}^{H N C}-K\right) T, N \rightarrow \infty
$$

where, $W_{i, T}=(T-2 K-1)\left(\frac{\tilde{\varepsilon}_{i} \emptyset_{i} \tilde{\varepsilon}_{i}}{\tilde{\varepsilon}_{i} M_{i} \tilde{\varepsilon}_{i}}\right)$ for $i=1,2, \ldots, N$. For more details, see (Dumitrescu and Hurlin, 2012).

\section{Analysis of Results}

Table 3.1 below reveals the results of the Dumitrescu-Hurlin Panel Causality test across the countries under study. At 5\% level of significance, it is evident to reject the null that mkt_val does not homogeneously cause $g d p$.This tends to imply that market value across the countries can be used to predict the value of $g d p$ in the long run. Similarly, there is evidence to reject the null that inflation does not homogenously cause $g d p$, this tends to imply, the causality effect of inflation on the economic growth of these African countries. The rejection of the null that $m k t \_v a l$ does not homogeneous cause $b n k \_c r$ is evident and statistically significant at $5 \%$ level of 
significance. There is also strong evidence to reject at 5\% level of significance, the null that bnk_cr does not homogeneously cause the inflation in Africa. The results provided in Table 3.1 tend to indicate one directional causality between the stock market and economic growth, inflation and economic growth, stock market and banking system, and banking system and inflation respectively. The matrix representation of the information contained in Table 3.1 is given below:

Table 3.1: Dumitrescu-Hurlin Panel Non-causality Test

\begin{tabular}{|c|c|c|c|}
\hline Null Hypothesis: & W-Stat. & Zbar-Stat. & p-value \\
\hline mkt_val does not homogeneously cause gdp & 4.81593 & 2.76203 & 0.0057 \\
\hline$g d p$ does not homogeneously cause $m k t$ _val & 1.22246 & -1.06464 & 0.2870 \\
\hline$b n k \_c r$ does not homogeneously cause $g d p$ & 1.65912 & -0.59964 & 0.5487 \\
\hline$g d p$ does not homogeneously cause $b n k \_c r$ & 3.82918 & 1.71124 & 0.0870 \\
\hline$m 2 \_m 1$ does not homogeneously cause $g d p$ & 2.17561 & -0.04964 & 0.9604 \\
\hline$g d p$ does not homogeneously cause $m 2_{-} m l$ & 2.35886 & 0.14550 & 0.8843 \\
\hline inf does not homogeneously cause $g d p$ & 6.37498 & 4.42225 & 0.0000 \\
\hline$g d p$ does not homogeneously cause inf & 1.40855 & -0.86648 & 0.3862 \\
\hline bnk_cr does not homogeneously cause mkt_val & 1.23800 & -1.04810 & 0.2946 \\
\hline mkt_val does not homogeneously cause $b n k \_c r$ & 8.22008 & 6.38709 & 0.00000 \\
\hline$m 2 \_m 1$ does not homogeneously cause mkt_val & 3.58526 & 1.45149 & 0.1466 \\
\hline$m k t \_v a l$ does not homogeneously cause $m 2_{-} m 1$ & 2.95950 & 0.78513 & 0.4324 \\
\hline inf does not homogeneously cause mkt_val & 2.61589 & 0.41922 & 0.6751 \\
\hline mkt_val does not homogeneously cause $i n f$ & 2.83402 & 0.65150 & 0.5147 \\
\hline$m 2 \_m l$ does not homogeneously cause $b n k \_c r$ & 1.79476 & -0.45520 & 0.6490 \\
\hline$b n k \_c r$ does not homogeneously cause $m 2_{-} m l$ & 3.62695 & 1.49589 & 0.1347 \\
\hline inf does not homogeneously cause bnk_cr & 3.42245 & 1.27812 & 0.2012 \\
\hline$b n k \_c r$ does not homogeneously cause inf & 4.52942 & 2.45692 & 0.0140 \\
\hline inf does not homogeneously cause $m 2 \_m 1$ & 2.73011 & 0.54084 & 0.5886 \\
\hline$m 2 \mathrm{ml}$ does not homogeneously cause inf & 1.72679 & -0.52759 & 0.5978 \\
\hline
\end{tabular}

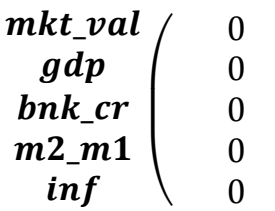

$\left.\begin{array}{ccc}\multicolumn{4}{c}{\boldsymbol{m k t} \text { valgdpbnk_crm2_m1inf }} \\ \overrightarrow{0} & 0 & 0 \\ 0 & 0 & 0 \\ 0 & 0 & \overrightarrow{0} \\ 0 & 0 & 0 \\ 0 & 0 & 0\end{array}\right)$,

where, $\rightarrow$ implies that there is significant causality running from the row-variables to the column-variables and Oimplies that there is no significant causality running from the row-variables to the column-variables.

\section{Conclusion}

This research work was set out to investigate the panel of seven African Countries with a view to determine the direction of causality between the financial development and economic growth in Africa. The results across the countries under study revealed that it is strongly evident to reject the null that market value does not homogeneously cause economic growth. This tends to imply that market value across the countries can be used to predict the economic growth in the long run. Also, there is tendency of causality effect of inflation on the economic growth of these African countries.

\section{Reference}

[1] Adnan, N. (2011).Measurement of Financial Development: A Fresh Approach. 8th

[2] International Conference on Islamic Economics and Finance. www.qfis.edu.qa/app/media/234. Retrieved on 19/05/13, Time: 2:15pm

[3] Adusei, M. (2013). Financial Development and Economic Growth: Evidence from Ghana

[4] The International Journal of Business and Finance Research, Vol. 7, No. 5, p. 61-76.

[5] Allen, F. and Gale, D. (1999). Comparing Financial Systems. MA: MIT Press, Cambridge, London.

[6] Babayemi, A. W. and Asare B. K. (2014). African Stock Markets, Banks and the Long-run Economic Growth. Equity Journal of Science and Technology, Vol. 2, No. 1 p.1-15.Beck, T. and Levin R. (2002). Industry Growth and Capital Allocation: *1: Does Having a Market- or Bank-Based System Matter? Journal of Financial Economics, Elsevier, Vol. 64, No 2, 147-180

[7] Bencivenga, V. R. and Smith, B. D. (1991). Financial Intermediation and Endogenous Growth. Journal of Economic Theories, Vol. 58, p. 195-209.

[8] Bencivenga, V. R., Smith, B. D. and Starr, R. M. (1995). Transaction Costs, Technological Choice, and Endogenous Growth. Journal of Economic Theories, Vol. 67, No. 1, p. 53-117. 
[9] Dumitrescu, E. and Hurlin, C. (2012). Testing for Granger Non-causality in Heterogeneous Panels, Economic Modeling, Vol. 29, p. 1450-1460.

[10] Granger, C. W. J. (1969). Investigating Causal Relations by Econometric Models and Cross-Spectral Methods, Econometrica, Vol. 37, p. 424-438.

[11] Indrani, C. (2007). Does Financial Development Cause Economic Growth? The case of India. Institute of Development Studies Kolkata. www.idsk.org. Retrieved on 12/11/2010, Time: 3.45pm. Laurent, C., Christian, G. and Franz, P. (2011). Stock Markets, Banks and Long- run

[12] Economic Growth: A Panel Cointegration-Based Analysis. Preprint submitted to Elsevier. Retrieved on 02/04/12, Time: 3:013am

[13] Levine, R. (2002). Bank Based or Market-Based Financial Systems: Which is better?

[14] National Bureau of Economic Research (NBER) Working Paper, No. 9138. JEL No. G0, K2, O4.https://ideas.repec.org/p/nbr/nberwo/9138.html. Retrieved on 11/05/12, Time: 2:03pm.

[15] Nile Capital Management (2011). Nile Pan Africa Fund (Nafax) - 2010

[16] Performance Update. http://www.nilefunds.com. Retrieved on 20/09/2011, Time: 2:47pm. 